\title{
Cardiovascular effects of dobutamine stress testing in women with suspected coronary artery disease
}

Peter Blomstrand, Jan Engvall, Eva Swahn, Kåge Säfström, Olav Thulesius, Bengt Wranne

\begin{abstract}
Objective-To investigate the central and peripheral haemodynamic response to dobutamine stress testing in women with suspected ischaemic heart disease and to seek an explanation for the hypotension phenomenon.

Design-18 women aged 54-73 years were investigated with Doppler echocardiography and venous occlusion plethysmography during intravenous infusion of dobutamine 5-10 d after an episode of unstable angina.
\end{abstract}

Results-An average peak dose of 33 (SD 9.7) $\mu \mathrm{g} / \mathrm{kg} / \mathrm{min}$ was given. Heart rate and cardiac output increased by $49 \%$ and $59 \%$, respectively $(P<0.001)$. Total and leg peripheral vascular resistance decreased by $44 \%$ and $26 \%$, respectively $(P<0.001)$. Four patients developed hypotension (decrease in systolic blood pressure $>10$ $\mathrm{mm} \mathrm{Hg}$ ), one of whom had a paradoxical bradycardia and two a low increase in cardiac output. Patients with hypotension had a more pronounced decrease in total peripheral vascular resistance but a similar change in leg peripheral vascular resistance compared with patients without hypotension.

Conclusions-Dobutamine infusion leads to marked peripheral vasodilatation and an increase in cardiac output. Some patients experience hypotension during the test for reasons which include paradoxical vasovagal reactions and diminished capacity for adequate increase in cardiac output. There is also a disparity between the pattern of total and leg peripheral vascular resistance in patients with hypotension which might reflect a baroreceptor mediated compensatory increase in vasoconstrictor tone of muscle vessels not matched in other vascular territories.

(Heart 1996;75:463-468)

Keywords: echocardiography; dobutamine; vascular resistance; plethysmography

Dobutamine stress echocardiography has been used with increasing frequency as a method for detecting coronary artery disease. ${ }^{12}$ Some groups have reported a fall in systolic blood pressure during the test. ${ }^{3-5}$ Whereas exercise induced hypotension has been recognised as an indicator of severe coronary artery disease, ${ }^{6}$ hypotension during dobutamine stress testing is not associated with advanced coronary disease or an adverse prognosis. ${ }^{45}$ The cause of hypotension is unclear, but myocardial ischaemia, valvar obstructive disease, obstructive cardiomyopathy, and vasovagal reflexes have been mentioned as possible mechanisms. ${ }^{3-5}$ Furthermore, an increased incidence of hypotension has been reported in older patients, women, and patients not on $\beta$ blockers. ${ }^{5}$ Dobutamine is a synthetic catecholamine which stimulates postsynaptic $\alpha$ and $\beta$ receptors of the cardiovascular system. The predominant postsynaptic adrenoreceptor of the heart is of the $\beta_{1}$ subtype which mediates a positive inotropic and chronotropic effect. Postsynaptic $\alpha_{1}$ and $\beta_{2}$ receptors of peripheral vessels mediate vasoconstriction and vasodilatation respectively. Dobutamine infusion leads to a complex haemodynamic alteration since it directly stimulates the adrenoreceptors of the heart and the vascular bed but also indirectly acts on the cardiovascular system through reflex inhibition of sympathetic tone and vasovagal reactions. In a previous study we investigated the haemodynamic response to dobutamine in healthy women and found a marked increase in heart rate and cardiac output and a marked decrease in peripheral vascular resistance. ${ }^{7}$ The cardiovascular response was dose and age dependent and hypotension was uncommon. However, studies in patients are lacking.

The aim of our present study was to investigate the central and peripheral haemodynamic alterations during dobutamine stress testing with blood pressure measurement, Doppler, echocardiography, and venous occlusion plethysmography in a group of women with objective signs of coronary artery disease.

\section{Patients}

\section{PATIENTS}

Eighteen women with a mean age of 65 years (range 54-73), weight 73 (SD 16) kg, and height 162 (4) $\mathrm{cm}$ were investigated as part of a prospective study of ischaemia and risk indicators in unstable coronary artery disease in women (IRIS). Postmenopausal women admitted to the coronary care unit with unstable coronary artery disease, that is, new onset or progressive angina pectoris, angina at rest, and occurrence of ST depression ( $\geqslant 0.1 \mathrm{mV}$ ) or development of non-Q-wave myocardial infarction ( $T$ wave inversion by $>0.1 \mathrm{mV}$ ), were included in the study. Dobutamine echocardiography was performed 5-10 d after 
an unstable episode. At time of the investigations, all patients were in sinus rhythm and clinically stable. None had undergone coronary artery bypass surgery or showed signs of aortic valvular disease. The electrocardiogram showed no signs of left ventricular hypertrophy or left bundle branch block. Patients with intermittent claudication and a low systolic ankle blood pressure or a history of arrhythmias such as atrial fibrillation, supraventricular tachycardia, or multiple ventricular beats at rest were excluded. All patients were on medical treatment, 16 receiving selective $\beta_{1}$ blocking agents and one an unselective $\beta$ blocker. Five were treated with calcium antagonists, four with long acting nitrates, two with diuretics, and two with angiotensin converting enzyme (ACE) inhibitors. To avoid dehydration the patients did not fast before the test.

The protocol was approved by the ethics committee of Linköping University Hospital and informed consent was obtained from all patients.

\section{DOBUTAMINE INFUSION PROTOCOL}

Dobutamine was given intravenously beginning at a dose of $5 \mu \mathrm{g} / \mathrm{kg}$ body weight per minute and increased in steps every sixth minute to $10,20,30$, and $40 \mu \mathrm{g} / \mathrm{kg} / \mathrm{min}$. The protocol was identical to that used in a previously reported study of healthy women, and 6 min steps were used because of the extensive study protocol. ${ }^{7}$ A 12-lead electrocardiogram was continuously recorded before the dobutamine infusion, throughout the infusion, and up to $6 \mathrm{~min}$ after it was discontinued. Blood pressure was determined by the auscultatory method at rest, during the infusion (at $2 \mathrm{~min}$ intervals), and 2, 4, and $6 \mathrm{~min}$ after the test. Mean arterial blood pressure was calculated as diastolic pressure + one third of the pulse pressure. Preset criteria for interruption of infusion before peak dose was reached were: (1) $\geqslant 4 \mathrm{~mm}$ ST segment depression on the electrocardiogram in a lead with normal ST segment at rest, (2) significant side effects or arrhythmias, (3) achievement of $85 \%$ of the age predicted maximum heart rate $(220$ minus age), (4) stress induced wall motion abnormalities involving two or more segments, (5) strong chest pain, (6) decrease in systolic blood pressure of $>20 \mathrm{~mm} \mathrm{Hg}$.

\section{ECHOCARDIOGRAPHY}

Cross sectional echocardiography was performed with the subjects in the left recumbent position at rest and during the dobutamine infusion, using six standard views (apical two, three, and four chamber views, parasternal long axis, and short axis views at papillary muscle and chorda level). ${ }^{8}$ Images were obtained using a combined $3.25 \mathrm{MHz}$ cross sectional imaging and $2.5 \mathrm{MHz}$ pulsed Doppler device (Vingmed CFM 800, Vingmed Sound). The recordings were stored on video tapes, optical discs, and paper printouts. The electrocardiographic chest electrodes were positioned so as not to cover the marked site for the echo acoustic window. Stroke volume was determined as the product of the subaortic flow area and the temporal velocity profile in the left ventricular outflow tract. ${ }^{9}$ The subvalvar aortic diameter was measured in the parasternal long axis view before the infusion and at peak dose of dobutamine and calculated as the mean of two measurements. The flow velocity was measured with pulsed wave Doppler with the sample volume placed in the middle of the left ventricular outflow tract in the apical five chamber view at rest and at peak dose dobutamine and calculated as mean of three measurements. The coefficient of variation in measuring the subaortic area is $4 \%$ at our department. ${ }^{10}$ The interobserver variability in determination of subvalvar flow velocity integral is 2.4 (SD 1.5)\%. ${ }^{9}$ Cardiac output was derived using the formula: left ventricular outflow tract cross sectional area $\times$ flow velocity integral $\times$ heart rate. Total peripheral vascular resistance was calculated as mean arterial blood pressure divided by cardiac output.

The cross sectional recordings were analysed independently by two observers, having several years of experience with stress echocardiography. The left ventricle was divided into 16 segments for analysis and the wall motion of each segment was classified according to a six grade scale: $0=$ not visualised, $1=$ normal, $2=$ hypokinesia, $3=$ akinesia, $4=$ dyskinesia, and $5=$ aneurysm. ${ }^{8}$ Echocardiograms were interpreted without knowledge of clinical data or coronary angiographic findings. When there was a disagreement about the result, the two observers together reviewed the study and reached a consensus on the grading. The interobserver agreement with regard to segmental analysis was $83 \%$. A wall motion index was derived representing the sum of all scores divided by the number of segments visualised in each patient.

\section{VENOUS OCCLUSION PLETHYSMOGRAPHY}

Plethysmographic recordings were obtained from the right leg with the subjects lying on the left side. The right leg was slightly elevated, supported with pillows at knee and ankle level and raised approximately $10^{\circ}$ above the horizontal level. A mercury-in-silastic strain gauge plethysmograph (Medimatic SP2) was used with a thin tubing placed around the right calf where the circumference was largest. An $8 \mathrm{~cm}$ wide blood pressure cuff was applied on the distal part of the thigh, proximal to the knee, and the venous outflow from the calf was occluded with a pressure of $80 \mathrm{~mm} \mathrm{Hg}$ for a period of $10 \mathrm{~s}$. During venous occlusion, the arterial flow into the calf produced swelling of the leg, stretching of the gauge, and increased electrical resistance proportional to the increase in calf volume. From changes of calf circumference per unit time, muscle blood flow can be calculated and expressed as $\mathrm{ml} / \mathrm{min} /$ litre tissue. ${ }^{11}$ Recordings were obtained three to five times at rest and three times at peak dose dobutamine infusion. The coefficient of variation in leg flow measurement was $16 \%$. Peripheral leg blood flow resistance was calculated as mean arterial pressure divided by 
Table 1 Haemodynamic variables at rest and during dobutamine infusion

\begin{tabular}{|c|c|c|c|}
\hline & Rest & Peak dose & $P$ \\
\hline Heart rate (beats/min) & $61(8)$ & $91(13)$ & $0 \cdot 001$ \\
\hline Systolic blood pressure $(\mathrm{mm} \mathrm{Hg})$ & $131(22)$ & $131(29)$ & NS \\
\hline Diastolic blood pressure ( $\mathrm{mm} \mathrm{Hg}$ ) & $69(9)$ & $53(18)$ & 0.001 \\
\hline Wall motion index & $1.34(0.40)$ & $1.24(0.35)$ & 0.01 \\
\hline $\mathrm{V}_{\max } \mathrm{LVOT}(\mathrm{m} / \mathrm{s})$ & $1 \cdot 0(0 \cdot 1)$ & $1 \cdot 5(0.4)$ & 0.001 \\
\hline VTILVOT $(\mathrm{cm})$ & $22 \cdot 4(2 \cdot 5)$ & $25 \cdot 6(4 \cdot 1)$ & 0.01 \\
\hline Stroke volume $(\mathrm{ml})$ & $70(13)$ & $75(15)$ & NS \\
\hline Cardiac output (litre/min) & $4 \cdot 2(0 \cdot 8)$ & $6 \cdot 7(1 \cdot 5)$ & 0.001 \\
\hline TPR (mm Hg/litre/min) & $21 \cdot 7(3 \cdot 7)$ & $12 \cdot 1(2 \cdot 5)$ & 0.001 \\
\hline Leg flow ( $\mathrm{ml} / \mathrm{min} /$ litre tissue) & $11 \cdot 7(3 \cdot 2)$ & $14 \cdot 6(5 \cdot 4)$ & 0.05 \\
\hline $\mathrm{LPR}(\mathrm{mm} \mathrm{Hg} / \mathrm{ml} / \mathrm{min} /$ litre tissue) & $8 \cdot 4(2 \cdot 3)$ & $6 \cdot 2(2 \cdot 3)$ & 0.001 \\
\hline
\end{tabular}

Data means (SD). Rest, preinfusion level; leg flow, blood flow in the right leg; LPR, leg peripheral vascular resistance; LVOT, left ventricular outflow tract; TPR, total peripheral vascular resistance; $\mathrm{V}_{\max }$, maxiumum systolic blood flow velocity; VTI, systolic blood flow velocity time integral; wall motion index, the sum of all left ventricular segmental wall motion scores divided by the number of segments visualised.

blood flow and expressed in peripheral resistance units as $\mathrm{mm} \mathrm{Hg} / \mathrm{ml} / \mathrm{min} /$ litre tissue. ${ }^{12}$

\section{CORONARY ANGIOGRAPHY}

Coronary angiography was performed 50 to $70 \mathrm{~d}$ after inclusion in all patients but one. The coronary arteries were visualised in multiple projections using a Siemens VACI Digitron 3. Coronary artery disease was considered significant if a $50 \%$ or more reduction in luminary diameter of a major epicardial coronary artery was present when analysed visually. Four patients had a coronary angiogram without significant coronary lesions, five had one vessel disease, seven two vessel disease, and one three vessel disease.

\section{STATISTICS}

Height, weight, heart rate, blood pressure, and echocardiographic and plethysmographic results are given as mean (SD). The change in haemodynamic variables during dobutamine infusion were analysed using the paired $t$ test. The difference in haemodynamic variables between the patients in the present study and the healthy women in the study of Blomstrand

Table 2 Background data and haemodynamic variables in patients developing hypotension during dobutamine infusion

\begin{tabular}{|c|c|c|c|c|}
\hline & \multicolumn{4}{|l|}{ Patient } \\
\hline & 1 & 2 & 3 & 4 \\
\hline $\begin{array}{l}\text { Age (years) } \\
\text { Weight }(\mathrm{kg}) \\
\text { Peak dose }(\mu \mathrm{g} / \mathrm{kg} / \mathrm{min}) \\
\text { No of obstructed vessels }\end{array}$ & $\begin{array}{r}66 \\
102 \\
40 \\
3\end{array}$ & $\begin{array}{r}62 \\
66 \\
40 \\
0\end{array}$ & $\begin{array}{r}72 \\
84 \\
30 \\
1\end{array}$ & $\begin{array}{r}74 \\
55 \\
40 \\
2\end{array}$ \\
\hline $\begin{array}{l}\text { Medical treatment } \\
\beta \text { Blocker } \\
\text { Calcium antagonist } \\
\text { Long acting nitrate } \\
\text { Diuretic } \\
\text { ACE inhibitor }\end{array}$ & $\begin{array}{l}\text { Yes } \\
\text { Yes } \\
\text { Yes } \\
\text { Yes } \\
\text { No }\end{array}$ & $\begin{array}{l}\text { Yes } \\
\text { No } \\
\text { Yes } \\
\text { No } \\
\text { No }\end{array}$ & $\begin{array}{l}\text { Yes } \\
\text { No } \\
\text { No } \\
\text { No } \\
\text { No }\end{array}$ & $\begin{array}{l}\text { Yes } \\
\text { No } \\
\text { No } \\
\text { No } \\
\text { No }\end{array}$ \\
\hline $\begin{array}{l}\text { Haemodynamic alterations (rest/peak dose) } \\
\text { Heart rate (beats/min) } \\
\text { Systolic blood pressure (mm Hg) } \\
\text { Diastolic blood pressure (mm Hg) } \\
\text { Wall motion index } \\
\mathrm{V}_{\max \mathrm{LVOT}(\mathrm{m} / \mathrm{s})} \\
\text { Stroke volume (ml) } \\
\text { Cardiac output (litre/min) } \\
\text { TPR (mm } \mathrm{Hg} / \text { litre/min) } \\
\mathrm{Leg} \text { flow }(\mathrm{ml} / \mathrm{min} / \mathrm{litre} \text { tissue) } \\
\mathrm{LPR}(\mathrm{mm} \mathrm{Hg} / \mathrm{ml} / \mathrm{min} / \text { litre tissue) }\end{array}$ & $\begin{array}{l}64 / 69 \\
145 / 105 \\
90 / 60 \\
1 \cdot 25 / 1 \cdot 19 \\
1 \cdot 0 / 1 \cdot 2 \\
88 / 106 \\
6 \cdot 6 / 7 \cdot 3 \\
19 \cdot 2 / 10 \cdot 3 \\
18 \cdot 0 / 10 \cdot 1 \\
6 \cdot 0 / 7 \cdot 4\end{array}$ & $\begin{array}{l}59 / 93 \\
130 / 115 \\
65 / 40 \\
1 \cdot 00 / 1 \cdot 00 \\
0 \cdot 9 / 1 \cdot 41 \\
50 / 49 \\
3 \cdot 0 / 4 \cdot 6 \\
29 \cdot 3 / 14 \cdot 2 \\
17 \cdot 4 / 15 \cdot 8 \\
5 \cdot 3 / 4 \cdot 1\end{array}$ & $\begin{array}{c}59 / 86 \\
130 / 80 \\
75 / 60 \\
1 \cdot 87 / 1 \cdot 67 \\
1 \cdot 0 / 1 \cdot 4 \\
712 / 55 \\
4 \cdot 2 / 4 \cdot 8 \\
18 \cdot 7 / 13 \cdot 6 \\
8 \cdot 6 / 8 \cdot 6 \\
11 \cdot 4 / 8 \cdot 1\end{array}$ & $\begin{array}{l}66 / 90 \\
170 / 145 \\
75 / 50 \\
1 \cdot 56 / 1 \cdot 50 \\
1 \cdot 0 / 2 \cdot 0 \\
55 / 89 \\
3 \cdot 6 / 8 \cdot 0 \\
29 \cdot 3 / 10 \cdot 1 \\
11 \cdot 5 / 9 \cdot 6 \\
13 \cdot 0 / 8 \cdot 5\end{array}$ \\
\hline
\end{tabular}

The haemodynamic variables are at rest, before the infusion, and at peak dose dobutamine infusion.

Rest, preinfusion level; leg flow, blood flow in the right leg; LPR, leg peripheral vascular resistance; LVOT, left ventricular outflow tract; TPR, total peripheral vascular resistance; $V_{\text {max }}$, maxiumum systolic blood flow velocity; wall motion index, the sum of all left ventricular segmental wal
motion scores divided by the number of segments visualised. et $a l^{7}$ the difference between patients with wall motion index $\geqslant 1.25$ and $<1.25$, and difference between patients with and without hypotension during dobutamine infusion were analysed using the unpaired $t$ test. Two sided tests were used throughout.

\section{Results}

No complications were seen in connection with the tests. An average peak dose of dobutamine of $33(9 \cdot 7) \mu \mathrm{g} / \mathrm{kg} / \mathrm{min}$ was given. The test was terminated at a peak dose of $10 \mu \mathrm{g} / \mathrm{kg} / \mathrm{min}$ in one patient, $20 \mu \mathrm{g} / \mathrm{kg} / \mathrm{min}$ in three, $30 \mu \mathrm{g} / \mathrm{kg} / \mathrm{min}$ in three, and $40 \mu \mathrm{g} / \mathrm{kg} / \mathrm{min}$ in 11. The test was interrupted because the maximum dose was reached in 10 patients, because of arrhythmias in two (ventricular arrhythmia in one and sinus arrhythmia with bradycardia and hypotension in one), discomfort in two (dyspnoea), decrease in systolic blood pressure in one, new wall motion abnormalities in one, ST depression in one, and angina in one. Occasional supraventricular and ventricular beats were recorded in another four subjects.

CENTRAL AND PERIPHERAL CIRCULATION

The heart rate increased from 61 (8) beats/ min at rest to 91 (13) at peak dose dobutamine $(P<0.001)$ (table 1$)$. Systolic blood pressure in the group as a whole was unchanged but diastolic blood pressure decreased from 69 (9) $\mathrm{mm} \mathrm{Hg}$ at rest to 53 (18) $\mathrm{mm} \mathrm{Hg}$ at peak dose $(\mathrm{P}<0.001)$. There was no significant change in stroke volume: 70 (13) $\mathrm{ml}$ before the infusion and 75 (15) $\mathrm{ml}$ at peak dose of dobutamine. However, because of the increase in heart rate (61-91 beats/min), cardiac output increased from $4.2(0.8)$ litres/min at rest to $6.7(1.5)$ at peak dose $(P<$ $0.001)$. Total peripheral vascular resistance decreased by $44 \%$. Leg blood flow increased by $25 \%$ and leg peripheral vascular resistance decreased by $26 \%$. A dynamic obstruction during the infusion, defined as a late peaking left ventricular outflow tract velocity that exceeded the velocity before the infusion by at least $1 \mathrm{~m} / \mathrm{s},{ }^{3}$ was not seen in any patient.

Left ventricular wall motion abnormalities were present in 16 patients before the test. New or worsened wall motion abnormalities during dobutamine infusion were only seen in four patients, and left ventricular function, as expressed by wall motion index, improved in most patients. To investigate the influence of left ventricular systolic function on the haemodynamic alterations during dobutamine infusion, patients with a wall motion index of $\geqslant 1.25(\mathrm{n}=8)$ at rest were compared with patients with an index of $<1.25(n=10)$. Patients with a wall motion index $\geqslant 1.25$ had a lower increase in systolic subvalvular flow velocity, +0.4 (0.3) v $+0.7(0.3) \mathrm{m} / \mathrm{s}(\mathrm{P}<$ $0.05)$, a tendency towards a lower increase in heart rate $[+22(17) v+35(14)$ beats $/ \mathrm{min}]$ $(P<0 \cdot 1)$, and a tendency towards a decrease in systolic blood pressure $[-11(27) \mathrm{mm} \mathrm{Hg}$, compared with an increase of $+8(17) \mathrm{mm} \mathrm{Hg}$ $(P<0 \cdot 1)$ in patients with an index of $<1 \cdot 25$ ]. 
Table 3 Comparison of 18 patients from the present study with 11 healthy women

\begin{tabular}{|c|c|c|c|}
\hline & $\begin{array}{l}\text { Patient } \\
n=18\end{array}$ & $\begin{array}{l}\text { Healthy women } \\
n=11\end{array}$ & $P$ \\
\hline Age (years) & $65(6)$ & $63(6)$ & NS \\
\hline Weight (kg) & $73(16)$ & $61(8)$ & 0.05 \\
\hline Peak dose $(\mu \mathrm{g} / \mathrm{kg} / \mathrm{min})$ & $33(9 \cdot 7)$ & $22(7 \cdot 5)$ & 0.01 \\
\hline$\Delta$ Heart rate (beats $/ \mathrm{min}$ ) & $29(16)$ & 47 (18) & 0.05 \\
\hline$\Delta$ Systolic blood pressure $(\mathrm{mm} \mathrm{Hg})$ & $0(23)$ & $7(13)$ & NS \\
\hline$\triangle \mathrm{Diastolic}$ blood pressure $(\mathrm{mm} \mathrm{Hg})$ & $-16(11)$ & $-15(14)$ & NS \\
\hline$\Delta \mathrm{V}_{\max } \mathrm{LVOT}(\mathrm{m} / \mathrm{s})$ & $0.6(0.3)$ & $0.9(0.3)$ & 0.01 \\
\hline$\triangle$ VTILVOT $(\mathrm{cm})$ & $3 \cdot 4(4 \cdot 0)$ & $5 \cdot 4(4 \cdot 0)$ & NS \\
\hline$\Delta$ Stroke volume $(\mathrm{ml})$ & $5(15)$ & $10(11)$ & NS \\
\hline$\Delta$ Cardiac output (litre/min) & $2 \cdot 5(1 \cdot 5)$ & $4 \cdot 1(1.9)$ & 0.05 \\
\hline$\triangle \mathrm{TPR}(\mathrm{mm} \mathrm{Hg} / \mathrm{litre} / \mathrm{min})$ & $-10 \cdot 6(4 \cdot 5)$ & $-10 \cdot 8(6 \cdot 6)$ & NS \\
\hline$\Delta$ Leg flow ( $\mathrm{ml} / \mathrm{min} /$ litre tissue $)$ & $3.1(5.5)$ & $8 \cdot 1(7 \cdot 0)$ & 0.05 \\
\hline$\triangle \mathrm{LPR}(\mathrm{mm} \mathrm{Hg} / \mathrm{ml} / \mathrm{min} /$ litre tissue $)$ & $-2 \cdot 2(2 \cdot 1)$ & $-2 \cdot 4(1 \cdot 7)$ & NS \\
\hline
\end{tabular}

Comparison of the patients in the present study and 11 healthy middle aged women. ${ }^{7}$ Data means (SD). $\Delta$, mean value at peak dose dobutamine minus rest (preinfusion) value; leg flow, blood flow in the right leg; LPR, leg peripheral vascular resistance; LVOT, left ventricular outflow tract; TPR, total peripheral vascular resistance; $\mathrm{V}_{\max }$, maxiumum systolic blood flow velocity; VTI, systolic blood flow velocity time integral.

\section{HYPOTENSION}

Four patients showed hypotension, defined as a drop in systolic blood pressure of $>10 \mathrm{~mm} \mathrm{Hg}$ on two subsequent recordings at peak dose dobutamine compared with rest (table 2).

The first woman was obese. She had a wall motion index of 1.25 and no new wall motion abnormalities during the test. Coronary angiography showed three vessel disease and she was treated with a $\beta_{1}$ blocking agent, a calcium antagonist, long acting nitrates, and diuretics. She received a peak dose of $40 \mu \mathrm{g} / \mathrm{kg} / \mathrm{min}$ but had a very low increase in heart rate $(+5$ beats/min) and cardiac output $(+0.7$ litres $/ \mathrm{min})$ despite a reduced total peripheral vascular resistance of $46 \%$.

The second patient had normal coronary angiography, normal wall motion at rest, and no signs of ischaemia during dobutamine infusion. Her change in heart rate, cardiac output, and peripheral vascular resistance did not differ from the other patients.
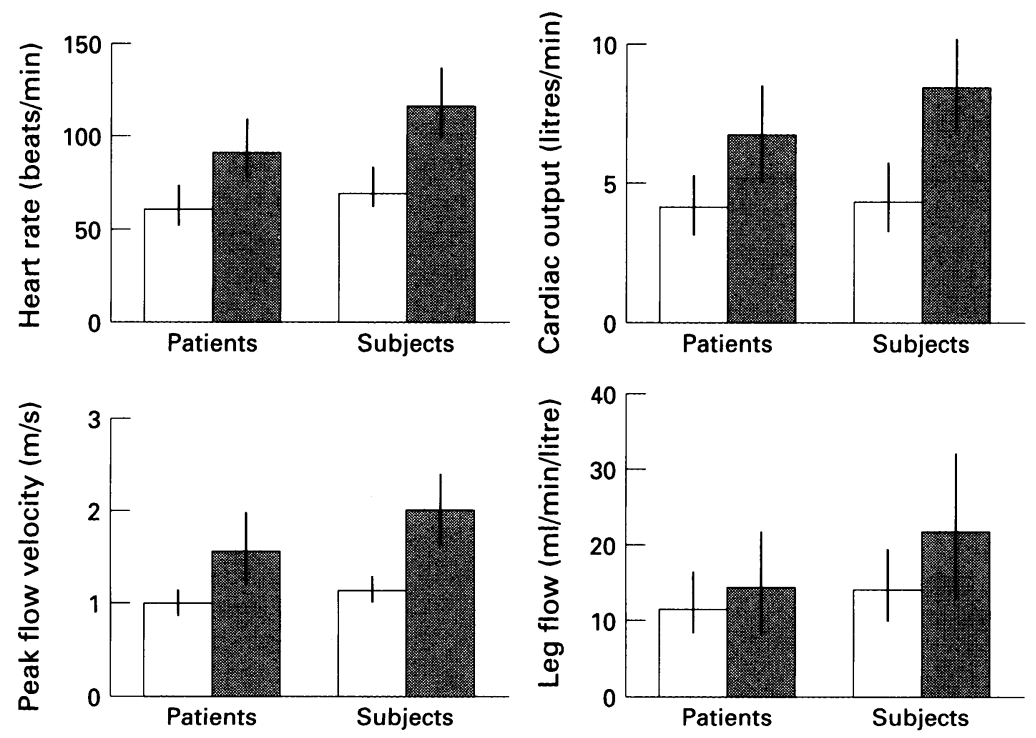

$\square$ Rest Peak dose

Comparison of heart rate, cardiac output, maximum systolic blood flow velocity in the left ventricular outflow tract (peak flow velocity), and blood flow in the right leg (leg flow) in 18 patients from the present study and 11 healthy middle aged women. ${ }^{7}$ Data are means, 18 patients from the present study and 11 healthy middle aged women.
bars $=S D$, at the preinfusion level (rest) and at peak dose dobutamine (peak dose). The alterations during dobutamine infusion were less pronounced in the patients than in the healthy subjects $(P<0 \cdot 05)$.
The third woman had severe left ventricular systolic dysfunction with a wall motion index of 1.87 at rest, but only one vessel disease on coronary angiography. She received a peak dose of $30 \mu \mathrm{g} / \mathrm{kg} / \mathrm{min}$, developed new wall motion abnormalities, and had a very low increase in cardiac output of $+0.5 \mathrm{litre} / \mathrm{min}$.

The fourth patient had impaired left ventricular function, a wall motion index of 1.56 at rest, and two vessel disease including a proximal obstruction on the left anterior descending coronary artery. She received a peak dobutamine dose of $40 \mu \mathrm{g} / \mathrm{kg} / \mathrm{min}$ and developed new wall motion abnormalities and a paradoxical decrease in heart rate from 103 beats/min to 76 beats/min at peak dose, just before the infusion was stopped.

These four patients had a more pronounced decrease in total peripheral vascular resistance, $-14.9(4.4) \mathrm{mm} \mathrm{Hg} / \mathrm{litre} / \mathrm{min}$, compared with $-9.3(3.9) \mathrm{mm} \mathrm{Hg} / \mathrm{litre} / \mathrm{min}$ in the other patients $(\mathrm{P}<0.05)$. Conversely, leg blood flow tended to decrease during dobutamine infusion in the hypotension group, at $-2.8(3.5)$ $\mathrm{ml} / \mathrm{min} /$ litre tissue compared with an increase of $+4.8(4.8)$ in the other patients $(P<0.01)$, and there was no difference in leg peripheral vascular resistance between the groups.

COMPARISON WITH HEALTHY WOMEN

In a previous study we investigated the haemodynamic response to dobutamine in 11 healthy women of comparable age to the patients in the present study. ${ }^{7}$ The patients in our present study received a higher peak dose of dobutamine, $33(9.7) \mu \mathrm{g} / \mathrm{kg} / \mathrm{min}$ compared with 22 $(7.5) \mu \mathrm{g} / \mathrm{kg} / \mathrm{min}$ in the normal subjects $(P<$ 0.01 ), but heart rate, maximum systolic blood flow velocity in the left ventricle outflow tract, cardiac output, and leg blood flow increased less in the patients compared with the healthy subjects (table 3) (figure). There was no difference in change of vascular resistance between the groups. Hypotension was seen in four out of 18 patients in the present study compared with one of 11 normal subjects.

\section{Discussion}

Hypotension was common in the present study $(22 \%)$ and of the same magnitude as reported in another recent study $(20 \%)$ of Marcovitz et al..$^{5}$ Rosamond et al ${ }^{4}$ found a hypotensive response in as many as $38 \%$ compared with only $9 \%$ in a study of healthy subjects previously published. However, the difference in the numbers of patients developing hypotension between these four studies is not significant. ${ }^{45}$ Marcovitz et al also reported an increased incidence of hypotension in older patients, women, and patients without $\beta$ blocker treatment. ${ }^{5}$ Dobutamine infusion leads to complex haemodynamic alterations, and patients with a hypotensive reaction during the test are a heterogeneous group. We shall therefore discuss the haemodynamic alterations to dobutamine and different possible mechanisms of hypotension separately.

$\beta$ Blocker treatment blunts the effects of dobutamine, especially the $\beta_{1}$ mediated 
inotropic and chronotropic effects on the heart. Non-selective $\beta$ blockers also negate the $\beta_{2}$ mediated vasodilatation. This is probably the reason why hypotension is less common in patients with $\beta$ blocker treatment and why our patients had a lower increase in heart rate and cardiac output compared with the healthy subjects, despite the fact that they received a higher peak dose of dobutamine. ${ }^{7}$

Elderly patients have diminished cardiovascular reflex responses and a reduced capacity to compensate adequately for changes in blood pressure, vascular resistance, and capacitance, and this might explain why hypotension is more common in them. ${ }^{13}$ It is also possible that control of blood pressure and the capacity to compensate for the haemodynamic changes induced by dobutamine are superior in healthy subjects compared with patients with atherosclerosis, coronary artery disease, and impaired left ventricular function. An imbalance between changes in cardiac output and peripheral vascular resistance during dobutamine infusion could explain the hypotensive reaction seen in two patients (RH-26, AC-20) in the present study. The latter patient (AC-20) had severe left ventricular dysfunction and developed new wall motion abnormalities which could explain her blunted increase in cardiac output. There was also a tendency towards a more blunted change in systolic blood pressure in patients with a wall motion index of $\geqslant 1.25$ than in patients with a wall motion index of $<1 \cdot 25$. Marcovitz et al proposed that myocardial ischaemia during dobutamine infusion may lead to a gradual onset of hypotension. ${ }^{5}$ However, in our study hypotension was not strongly associated with extensive wall motion abnormalities at rest or new wall motion abnormalities during dobutamine infusion.

Left ventricular function, as expressed by wall motion index, improved in most patients and this may appear paradoxical but can be explained on the basis of recruitment of areas with stunned or hibernated myocardium during dobutamine stimulation. It has been shown that the addition of atropine at peak dose dobutamine enhances the sensitivity of dobutamine stress echocardiography and it would probably have increased the number of patients with new or worsening of wall motion abnormalities in our study. ${ }^{14}$

Pellikka et al proposed that cavity obliteration was common in patients with a good left ventricular function and, in combination with mild dehydration, might be the cause of hypotension in patients with a very hyperkinetic left ventricle and without significant coronary artery disease. ${ }^{3}$ This is in line with our results; two healthy women developed an outflow obstruction in our previous study but no cavity obliteration was seen in the present study. ${ }^{7}$

It has been suggested that hypotension might be caused by the vasodilating effects of dobutamine. ${ }^{4}$ Dobutamine has a direct effect on arterial and venous tone, and also an indirect effect through reflectory withdrawal of sympathetic vasoconstrictor tone secondary to the increase in cardiac output. ${ }^{1516}$ A decrease in systemic vascular resistance of $30-40 \%$ during dobutamine infusion has been reported in patients. ${ }^{1}$ In the present study we found a decrease of $44 \%$ in total peripheral vascular resistance and $26 \%$ in leg peripheral vascular resistance. We found a more pronounced decrease in total peripheral vascular resistance in patients with hypotension compared with those without hypotension. Furthermore, in the hypotensive patients we noted a disparity between the pattern of total and leg peripheral vascular resistance. While total peripheral vascular resistance declined markedly, there was a decline in leg blood flow, consistent with vasoconstriction in muscle vessels. This reaction obviously reflects a baroreceptor mediated compensatory reaction not matched by reduction in other vascular territories. ${ }^{17}$

One patient in the present study (AN-18) developed a paradoxical bradycardia and a decrease in blood pressure at peak dose dobutamine. Exogenous catecholamine infusion during upright tilt testing has been used to elicit vasovagal reactions with symptomatic hypotension and bradycardia in patients with recurrent syncope of unknown origin. ${ }^{18}$ Mazeika et al found a paradoxical hypotension-bradycardia in seven of 50 patients undergoing dobutamine echocardiography. ${ }^{19}$ Vasovagal reactions could therefore be one explanation for the hypotension.

\section{LIMITATIONS OF THE STUDY}

Calculating mean arterial blood pressure as diastolic pressure + one third of the pulse pressure might underestimate the mean arterial blood pressure when heart rate and pulse pressure increases during dobutamine infusion. This could result in an overestimation of the decrease in peripheral vascular resistance. However, the change in pulse pressure was rather low compared to changes in flow so this possible error is of minor importance. Invasive blood pressure and cardiac output measurements would have been of advantage but were deemed unethical to use. Medical treatment could not be standardised because of different needs and contraindications in different patients. Withdrawal of antianginal treatment before a stress test is considered unethical in this group of patients in Sweden.

\section{CONCLUSIONS}

Dobutamine stress testing causes marked peripheral vasodilatation and increased cardiac output, but the changes are blunted in patients on $\beta$ blockers compared with healthy subjects. Hypotension is a common side effect of dobutamine in investigations on patients, the cause of which is probably multifactorial, including paradoxical vasovagal reactions and diminished capability to increase cardiac output adequately. Furthermore, there is a disparity between the pattern of total and leg peripheral vascular resistance in patients with hypotension which might reflect a baroreceptor mediated compensatory increase in vasoconstrictor tone of muscle vessels not matched in other vascular territories. This is the first 
study which provides a detailed central and peripheral haemodynamic analysis of the dobutamine stress test in women with coronary artery disease.

We thank Inger Ekman, Elisabeth Forström, and Elisabeth Logander for their help in this study, Anders Björkholm and Gunnar Wiklund for performing coronary angiography, and Tomas Larsson for statistical assistance. Financial support was given by grants from the County Council of Östergötland, University Hospital of Linköping, the Swedish Heart and Lung Foundation, the Swedish Medical Research Council (gran 9481), Vingmed Sound A/S, Horten, Norway, and Eli Lilly and Company

1 Piérard LA, Berthe C, Albert A, Carlier J, Kulbertus HE. Haemodynamic alterations during ischemia induced by dobutamine stress testing. Eur Heart $\mathcal{F}$ 1989;10:783-90.

2 Sawada SG, Douglas SS, Ryan T, et al. Echocardiographic detection of coronary artery disease during dobutamine infusion. Circulation 1991;83:1605-14.

3 Pellikka PA, Oh JK, Bailey KR, Nichols BA, Monahan $\mathrm{KH}$, Tajik AJ. Dynamic intraventricular obstruction during dobutamine stress echocardiography. Circulation 1992;86:1429-32.

4 Rosamond TL, Vacek JL, Hurwitz A, Rowland AJ Beauchamp GD, Crouse L. Hypotension during dobutamine stress echocardiography: Initial description and mine stress echocardiography: Initial descriptic

5 Marcovitz PA, Bach DS, Mathias W, Shayna V, Armstron WF. Paradoxic hypotension during dobutamine stress echocardiography: clinical and diagnostic implications. $f$ echocardiography: clinical and di

6 Thomson PD, Kelemen MH. Hypotension accompanying the onset of exertional angina a sign of severe compromise of left ventricular blood supply. Circulation 1975; 52:28-32.

7 Blomstrand P, Thulesius O, Wranne B. Cardiovascula effects of dobutamine stress testing in healthy women Clin Cardiol 1995;18:659-63.
8 Schiller NB, Shah PM, Crawford M, et al. Recommendations for quantitation of the left ventricle by two-dimensional echocardiography. $\mathcal{F} \mathrm{Am}$ Soc Echocardiogr 1989; 2:358-67.

9 Lewis JF, Kuo LC, Nelson JG, Limacher MC, Quinones MA. Pulsed Doppler echocardiographic determination of stroke volume and cardiac output: clinical validation of two new methods using the apical window. Circulation 1984;70:425-31.

10 Janerot Sjöberg B, Wranne B. Cardiac output determinated by ultrasound-Doppler: clinical applications. Clin Physiol by ultrasound-Doppl

11 Whitney RJ. The measurement of volume changes in human limbs. $\mathcal{F}$ Physiol (Lond) 1953;121:1-27.

12 Green HD, Rapela CE, Conrad MC. Resistance (conductance) and capacitance phenomena in terminal vascular beds. In: Hamilton WF, ed. Handbook of physiology. 2 . Circulation II. Baltimore: Williams and Wilkins, 1963 935-60.

13 Docherty JR. Cardiovascular responses in ageing. Pharmacol Rev 1990;42:103-25.

14 McNeill AJ, Fioretti PM, El-Said EM, Salustri A, Forste T, Roelandt JRTC. Enhanced sensitivity for detection of coronary artery disease by addition of atropine to dobutamine stress echocardiography. Am f Cardiol 1992;70 41-6.

15 Liang CS, Hood WB Jr. Dobutamine infusion in conscious dogs with and without autonomic nervous system inhibition: effects on systemic haemodynamics, regional blood fows and cardiac metabolism. I Pharmacol Exp Ther 1979;211:698-705.

16 Binkley PF, Murray KD, Watson KM, Myerowitz PD, Leier CV. Dobutamine increases cardiac output of the total artificial heart, implications for vascular contribution of inotropic agents to augmented ventricular function. Circulation 1991;84:1210-15.

17 Kirchheim HR Systemic arterial baroreceptor reflexes. Physiol Rev 1976;56:100-76.

18 Almquist A, Goldenberg IF, Milstein S, et al. Provocation of bradycardia and hypotension by isoproterenol and of bradycardia and hypotension by isoproterenol and upright posture in patients with

19 Mazeika PK, Nadazdin A, Oakley CM. Clinical signifcance of abrupt vasodepression during dobutamine stress echocardiography. Am $\mathcal{F}$ Cardiol 1992;69:1484-6. 